\title{
EFFECT OF DIGITAL WORKFLOW ON THE MARGINAL FIT OF LONG-SPAN IMPLANT-SUPPORTED BARS FOR KENNEDY II CLASS REMOVABLE PROSTHESES IN VITRO
}

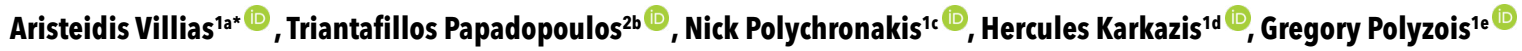 \\ 'Department of Prosthodontics, School of Dentistry, National and Kapodistrian University of Athens, Athens, Greece \\ ${ }^{2}$ Department of Biomaterials, School of Dentistry, National and Kapodistrian University of Athens, Athens, Greece

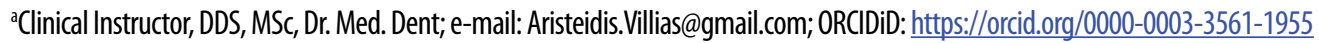 \\ bProfessor Emeritus, DDS, MSc, PhD; e-mail: trpapad@dent.uoa.gr; ORCIDiD: https://orcid.org/0000-0002-9533-6249 \\ 'Associate Professor, DDS, MSc, Dr. Dent; e-mail: nicpolis@dent.uoa.gr; ORCIDiD: https://orcid.org/0000-0001-7373-3414 \\ dProfessor, DDS, MSc, Dr. Dent; e-mail: hkarkaz@dent.uoa.gr; ORCIDiD: https://orcid.org/0000-0002-9003-2852 \\ eProfessor, DDS, MScD, Dr. Dent; e-mail: grepolyz@dent.uoa.gr; ORCIDiD: https://orcid.org/0000-0003-0032-039X
}

d) https://doi.org/10.25241/stomaeduj.2021.8(1).art. 4

Introduction The production procedures, including impressions, introduce errors affecting the passivity of fit. A completely digital workflow is possible nowadays because of the intraoral scanners (IOS). This study aimed to evaluate the effect of the impression technique (conventional versus digital) and the screw tightening sequence on the marginal discrepancy (MD) of implant-supported bars.

Methodology This laboratory study was conducted on a simulated Kennedy class II edentulous maxilla with three parallel implants in the edentulous quartile. The closed tray technique with a-silicon (CTM) and the intraoral scanning with the I-Tero ${ }^{\mathrm{TM}}$ system (IOS) were compared and three bars were manufactured from each technique. Depending on the screw tightening sequence (A11 and A17) 4 groups were created with 6 samples each. The MD was examined implementing 24 negative replicas, which were sectioned and studied under a stereomicroscope. The Horizontal Discrepancy (BHD), Vertical Discrepancy (BVD) and Conical Discrepancy $(B C D)$ of the bar were calculated on the means of the measurements of the horizontal, the vertical and the conical MD respectively. The descriptive statistics, normality tests, one-way ANOVA $(a=.05)$ and post-hoc Tukey's tests were run and the graphs were draw with SPSS.

Results There was a significant effect $(P<.05)$ of the impression technique combined with the screw tightening sequence on all variables. The post-hoc Tukey's tests revealed significant differences between all groups except from those of the same impression technique only for the BHD $(\mathrm{P}<.05)$.

Conclusion In this study all groups resulted in marginal discrepancies. The closed tray impression technique gave better results.

\section{KEYWORDS}

CAD/CAM; Digital Image Analysis; Implant-Supported Bar; Intraoral Scanner; Marginal Fit.

\section{INTRODUCTION}

The preservation of natural teeth is one of the goals of modern dentistry, resulting in a progressively increasing demand for partial dentures [1]. With the propagation of age, replacement of missing teeth is a common patient need [2]. Elderly patients are usually accompanied by general health issues, which also affect the dental treatment plan [3]. Therefore, the suggested dental treatment plans should be realistic, straightforward, versatile, aiming to restore the lost functionality and cover the esthetic needs of the patient. Removable partial dentures, either traditional or implant-supported are prostheses that

(c) (1) (2) OPEN ACCESS This is an Open Access article under the CC BY-NC 4.0 license. Peer-Reviewed Article

Citation: Villias A, Papadopoulos T, Polychronakis N, Karkazis H, Polyzois G. Effect of digital workflow on the marginal fit of long-span implant-supported bars for Kennedy II class removable prostheses in vitro. Stoma Edu J. 2021;8(1):33-44.

Received: January 19, 2021; Revised: February 18, 2021; Accepted: February 23, 2021; Published: February 25, 2021

*Corresponding author: Dr. Aristeidis Villias; Address: Kolokotroni 57-59, 18531 Piraeus, Greece;

Tel.: +304184843; Fax: +304184843; e-mail: Aristeidis.Villias@gmail.com

Copyright: $\odot 2021$ the Editorial Council for the Stomatology Edu Journal. 


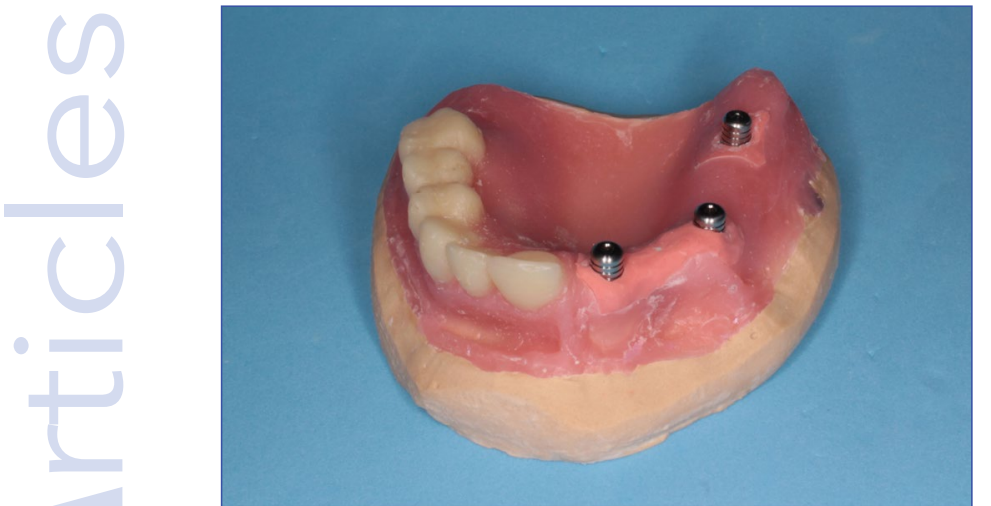

Figure 1. The pseudo-realistic model (PRM). A simulated partially edentulous, Kennedy class II maxilla, including three parallel $\left( \pm 1^{\circ}\right)$, standard, internal-heximplant analogsembedded in dental stone under $3-4 \mathrm{~mm}$ of simulated mucosa.

meet these requirements. The prosthodontic treatment of a Kennedy class II partially edentulous maxilla is demanding in terms of biomechanics and esthetics. A removable partial denture attached on an implant-supported bar might be an alternative treatment plan to a traditional partial denture [4].

For implant supported prostheses, passive fit is considered an ideal goal, preventing biological and mechanical complication in the future. The clinically accepted marginal fit (MF) might even surpass $200 \mu \mathrm{m}$ [5-7]. Furthermore, the shape of the internal connection implant features might affect the retention and the quality of the connection [8]. Ideally, discrepancies at the margin ought to be kept to a minimum. However, a passive fit and MF with undetectable discrepancies are technically almost impossible to achieve. Additionally, the correlation between the degree of MF and the incidence of clinical implications is yet to be defined. Nonetheless, it is clear that the various clinical and laboratory procedures introduce errors affecting the passivity of the fit.

The MF can be evaluated clinically with digital dental $X$-Rays, or with direct view if the margin can be directly observed [9]. Assessment of MF with an explorer can be unreliable [7]. Additionally, regarding implant supported prostheses, the explorer tip could scratch the delicate implant surface [10]. In vitro studies have a much wider armamentarium of methods to examine the MF [11]. The horizontal or the vertical marginal discrepancy at the restoration margin is reported in previous studies as an indication of the MF [6]. Destructive and non-destructive methods can be implemented [12-15]. The quality of the margin can be assessed with direct observation or through indirect procedures $[11,16,17]$. MF has been evaluated with image superimposition methods in combination with digital techniques as well $[12,18]$. Until recently impressions were only taken with impression materials placed in trays and inserted in the patient mouth. The procedure required a number of expendables, devices, skills and experience $[19,20]$. Introduction of intraoral scanners

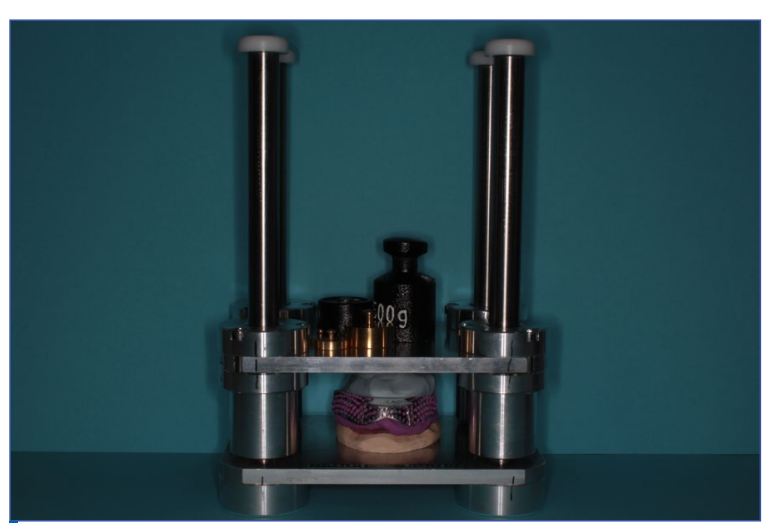

Figure 2. The pseudo-realistic model (PRM) with the seated tray placed under a constant axial load of $30 \mathrm{~N}$ at an axial loading device (ALD) for 12 min until the impression material was fully set.

(IOS) for digital impression facilitated the direct digitization of the oral environment without impression materials. Furthermore, the already established implementation of laboratory scanners to digitize the definitive casts affected multiple areas of dentistry including implantology [21].

The main advantages of digital impressions are the capability to immediately evaluate the virtual model chair-side, to evaluate the preparation depth, to modify the virtual model, they are producing less waste and they are time efficient. However, the IOS systems require a large investment and are associated with low quality of evidence when the resulting prostheses are compared for the marginal and internal fit with those from traditional impressions [22]. Furthermore, their accuracy can be affected by several parameters, such as the distance between implants, their inclination, their depth, the lighting conditions and the user experience [2332]. A fully digital approach in prosthetic dentistry is nowadays possible, given the fact that Computer Aided Design and Computer Added Manufacturing (CAD/CAM) procedures are widely acceptable over dental laboratories [33].

The introduction of IOS has offered a new way to register the implant location. In this direction implant manufacturers have introduced impression copings for digital procedures, the scan posts [34]. These scan posts are components of standard geometry accompanied with their corresponding digital design that facilitates the component recognition from the IOS software or the CAD software $[23,34]$. However, the implant system might affect the impression accuracy [23].

A challenge regarding edentulous areas is the lack of stable anatomical features on the mucosa that hinder accurate stitching of acquired images from the intraoral scanners [29,35-39]. Several studies have compared the accuracy of intraoral digital systems for crowns and short-span prostheses $[20,22]$. Scenarios implementing larger prosthesis have been run in simplified plaster models as well $[39,40]$. Furthermore, the introduction of digital 


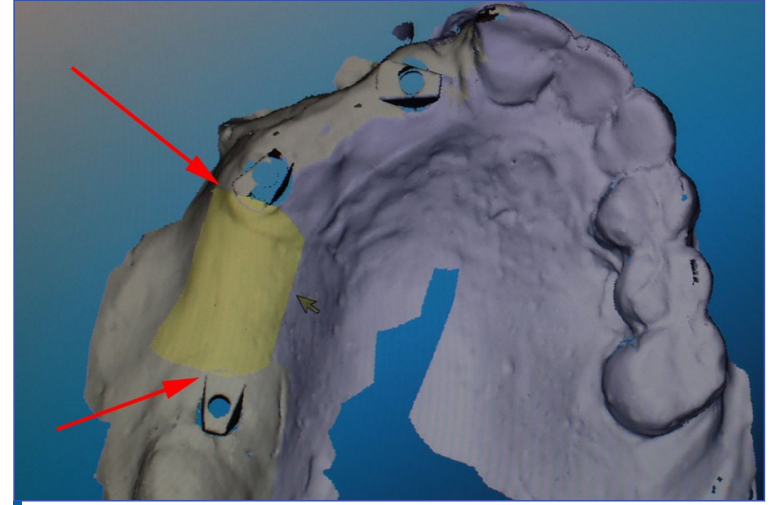

Figure 3. Simultaneous capture (red arrows) of the two most distant consecutive scanning posts attached to the underling implant analogs at positions 14 and 17 by the field of view of the scanner sensor (yellow highlighted area).

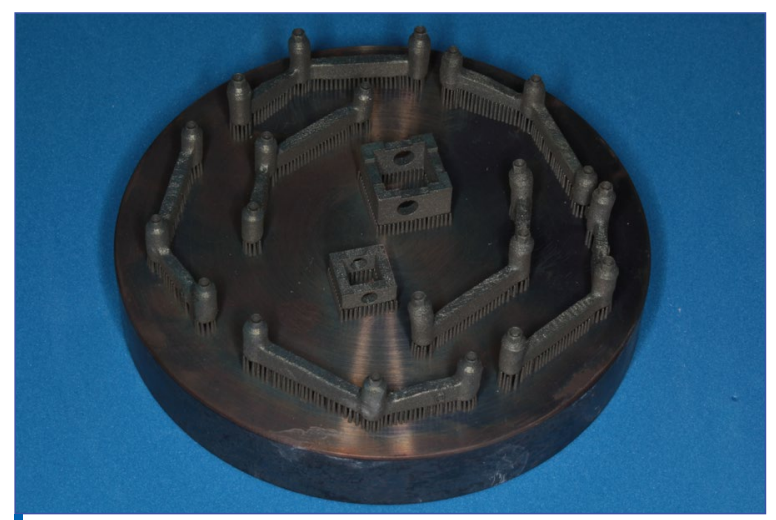

Figure 5. The parallel screw-retained $\mathrm{Co}-\mathrm{Cr}$ bars manufactured on one plate by a computer aided manufacturing (CAM) - Selective Laser Melting (SLM) technique utilizing a 3D printer seen after the appropriate stress relieving procedure.

techniques offer new ways in which the prostheses can be produced. However, there is not enough evidence regarding the resulting fit between implantsupported bars extending over a quadrant that are manufactured through a fully digital workflow and bars manufactured with a partially digital workflow. The purpose of this in vitro study was to compare the effect of a conventional impression technique and a technique implementing an intraoral scanner for digital impression on the marginal fit of implantsupported, long-span, parallel bars, manufactured with laser sintering technique. The effect of the screw tightening sequence was also examined. The null hypothesis was that the marginal fit of implant-supported bars would not be affected by the impression technique or the screw tightening sequence.

\section{MATERIALS AND METHODS}

This laboratory study was conducted on a simulated partially edentulous, Kennedy class II maxilla, which functioned as a pseudo-realistic model (PRM). The illustrated PRM (Fig. 1), included three, parallel $\left( \pm 1^{\circ}\right)$ standard, internal-hex implant analogs (Implant analog Internal Hex. Seven, MIS Implants Technologies Ltd, Lot: W17007917) embedded in

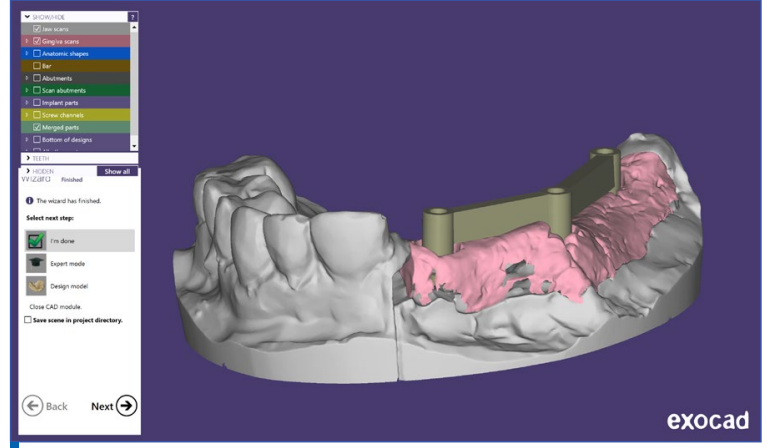

Figure 4. A screen image of a computer aided design (CAD) of a longspan, implant-supported, screw-retained at implant level, parallel bar on the digitized PRM created by an experienced dental technician with the exocad ${ }^{T M}$ software.

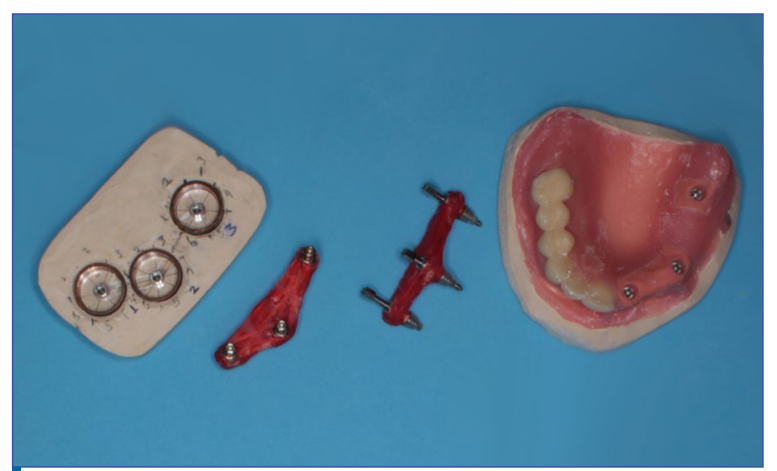

Figure 6. A customized Replica Production Device (RPD) utilized for the non-destructivenegative replica technique implemented in this study. The RPD with three incorporated parallel implant analogs, identical to those utilized in the PRM, placed at the same relevant positions as the PRM and verified by two interchangeable verification jigs, one produced on the PRM and the other on the RPD.

the dental stone. The analogs were located under $3-4 \mathrm{~mm}$ of simulated mucosa, at the locations of the lost maxillary right central incisor (11), first right premolar (14) and second right molar (17). The simulated teeth were acrylic and the maxillary mucosa was simulated with red pigmented acrylic resin.

\subsection{Impression techniques}

Two impression techniques were compared: the closed tray technique with monophase vinyl polysiloxane impression material (CTM) and the intraoral digital impression technique (IOS).

2.1.1. Closed Tray Technique

Initially three impression copings for the closed tray technique (Direct impression coping for closed tray, internal hex, MD-IT300-SP, MIS Implants Technologies Ltd, Dentsply Sirona, York, PA, USALOT\#: W16002796) were tightened with $10 \mathrm{Ncm}$ utilizing a torque ratchet on the implant analogs of the PRM. The fit of the impression copings was verified with digital X-rays (Belmond Phot-X II, Takara Belmont Corp, Osaka, Japan) captured with the parallel technique utilizing a sensor (Schick CDR USB Remote HS, Schick Technologies Inc, NY, USA). Next, the provided plastic rings were firmly seated on the impression copings. 
ITable 1. Summary of experimental groups.

\begin{tabular}{|l|l|}
\hline Table 1. Experimental groups \\
\hline Group I & CTM-A11 \\
\hline Group II & CTM-A17 \\
\hline Group III & IOS-A11 \\
\hline Group IV & IOS-A17 \\
\hline
\end{tabular}

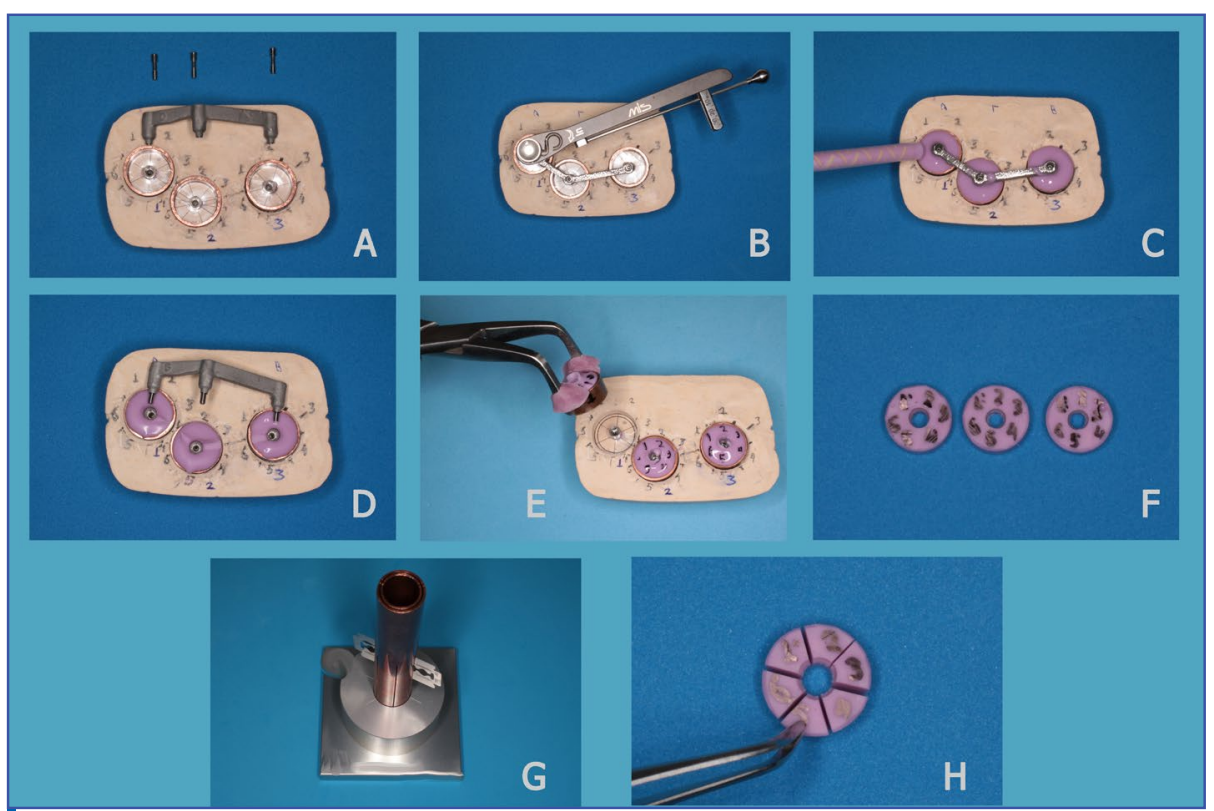

Figure 7. The production of negative replicas with a customized Replica Production Device (RPD) through a non-destructive method: A. A parallel bar before replication on the RPD with the implant analogs placed at the same relevant positions as the PRM. The three specialized copper trays seen in place surrounding the implant analogs. B. The bar seated and secured with three prosthetic screws on the RPD analogs following a preselected screw tightening sequence. C. Three negative replicas made simultaneously for each implant-bar connection from low viscosity addition silicone in the specialized cylindrical copper trays. D. The removed bar after polymerization of the A-silicone. E. The three specialized copper trays carefully detached from the RPD utilizing a modified crown forceps. F. The three removed-from-the-trays, trimmed and marked negative replicas corresponding to each implant-bar connection. G. The sample intersection device (SID) facilitating the standardized sectioning of each cylindrical negative replica in six $60^{\circ} \mathrm{sectors}$. H. One sectioned negative replica in six standardized marked slices, corresponding to six oriented observations for each of the three implant-bar connections of an implantsupported bar.

Monophase vinyl polysiloxane (Variotime Dynamix Monophase, Heraeus Kulzer GmbH, Germany, Lot: K010109) from an automix device (Variotime Dynamix Monophase, Heraeus Kulzer $\mathrm{GmbH}$, Germany) was used for the closed tray technique. $6 \pm 0.5 \mathrm{ml}$ of mixed material was loaded in each of the two syringes (Impression Jet, Heraeus Kulzer GmbH, Hanau, Germany) and the impression copings were covered with the material. Next, $25 \pm 1 \mathrm{ml}$ of mixed material was loaded on the perforated commercially available metal tray within $14 \pm 1 \mathrm{~s}$. The tray was appropriately seated on the PRM initially with a finger compression force $(15-30 \mathrm{~N})$ for $30 \mathrm{~s}$. This procedure took place within 2 min and 30 s, which was the material working time. Next, the PRM with the seated tray was placed under a constant axial load of $30 \mathrm{~N}$ for $12 \mathrm{~min}$ at an axial loading device (ALD) until the impression material was fully set (Fig. 2). Finally, the impression was removed from the PRM. Each impression coping was unscrewed from the PRM, placed on a new implant analog, tightened with $10 \mathrm{Ncm}$ with the Torque ratchet and the assembly was snapped on the corresponding plastic ring, which was embedded in the set impression material. In this manner three impressions were taken at room temperature $23 \pm 1^{\circ} \mathrm{C}, 50 \pm 10 \%$ Relative Humidity $(\mathrm{RH})$ with suitable light conditions (1100 Lux, 5500K). After $24 \mathrm{~h}$, each impression was used to produce a dental stone model. $48 \mathrm{~h}$ later, three scan posts were placed on the implant analogs of each model. Then, the three dental stone models were digitized with a laboratory optical scanner (Identica Blue ColLab scan v.2.003, Medit corp, Seoul, Korea) and the Standard Tessellation Language (STL) files were saved with a code name for later use. The PRM was scanned with the same scanner as well.

2.1.2. Intra-Oral Scanning

The Intra-Oral Scanner (IOS) I-tero (I-tero Model HDU-E Intra-oral Scanner Optical Impression Device, CADENT $^{\circledR}$ Ltd., Or Yehuda, IL-60212 Israel) was utilized for a direct digitization of the PRM. Three scan posts (Scan Post, int.hex. connection, SP, MIS Implants Technologies Ltd, Dentsply Sirona, York, PA, USA- LOT\#: W18002193) were placed on the implant analogs of the PRM. The scan posts on analogs 1114 and 14-17 were simultaneously captured with the IOS (Fig. 3). Their proper seating was checked with digital X-rays. Next, the PRM was scanned without powdering. The scanning took place in standardized light conditions within a light chamber with artificial 
ITable 2. Summary of descriptive statistics and normality tests.

\begin{tabular}{|c|c|c|c|c|c|c|c|c|c|}
\hline Group & Variable & $\mathrm{N}$ & Mean & $\mathrm{SE}$ & $\mathrm{SD}$ & Variance & Skewness & Kurtosis & $\begin{array}{c}\text { Shapiro- } \\
\text { Wilk (Sig.) }\end{array}$ \\
\hline CTM-A11 & BHD & 6 & 57.91 & 4.048 & 9.915 & 98.308 & .446 & -1.452 & .656 \\
\hline & BVD & 6 & 186.82 & 53.411 & 130.831 & 17116.719 & .110 & -2.954 & .068 \\
\hline & BCD & 6 & 26.39 & 2.207 & 5.406 & 29.225 & -.611 & -.792 & .486 \\
\hline CTM-A17 & BHD & 6 & 55.58 & 4.067 & 9.962 & 99.238 & -.034 & -3.068 & .070 \\
\hline & BVD & 6 & 180.52 & 51.932 & 127.208 & 16181.761 & .081 & -3.032 & .055 \\
\hline & BCD & 6 & 27.72 & 3.832 & 9.386 & 88.099 & .982 & 1.156 & .682 \\
\hline IOS-A11 & BHD & 6 & 313.59 & 89.160 & 218.396 & 47696.865 & -.428 & -2.007 & .242 \\
\hline & BVD & 6 & 469.63 & 119.117 & 291.777 & 85133.759 & -.585 & -1.895 & .111 \\
\hline & BCD & 6 & 423.99 & 147.872 & 362.212 & 131197.519 & .121 & -1.670 & .401 \\
\hline IOS-A17 & BHD & 6 & 315.90 & 89.370 & 218.912 & 47922.460 & -.534 & -2.049 & .180 \\
\hline & BVD & 6 & 484.44 & 122.869 & 300.967 & 90581.294 & -.685 & -1.998 & .061 \\
\hline & BCD & 6 & 407.97 & 136.074 & 333.313 & 111097.375 & -.099 & -1.595 & .511 \\
\hline
\end{tabular}

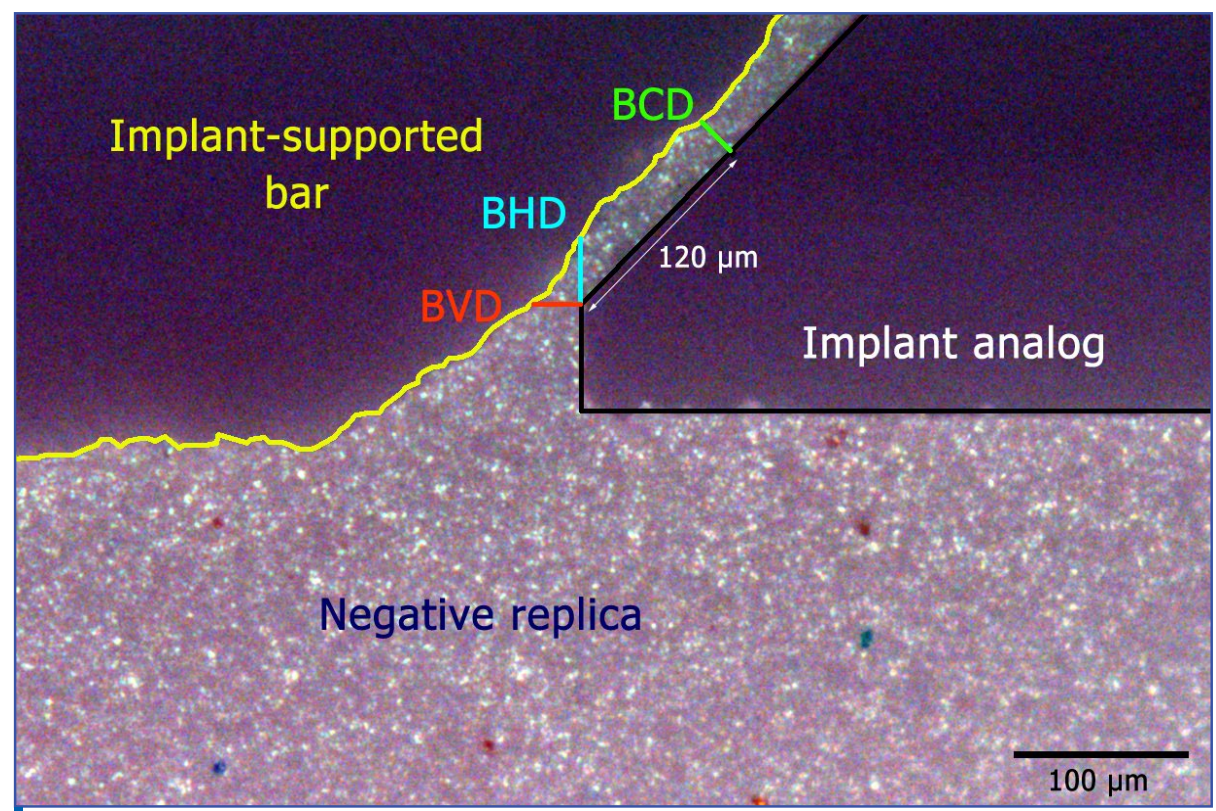

Figure 8. Demonstration of the analysis of the acquired digital photomicrograph. The standardized image shows a negative replica slice presenting the marginal fit at a sixth of the periphery of one of the three implant-bar connections of an implant-supported bar of this study. The empty space left by the RPD implant-analog on the right and the implant-supported bar on the left shown as dark areas in the upper part of the photomicrograph. The space surrounding the analog-bar assembly presented as the purple illuminated area. The gap between the connected components presented as a characteristic elongated light purple protrusion towards the dark area of the image. The section of the bar surface traced in yellow and the implant analog surface section traced in black. The dependent variables Bar Horizontal Discrepancy (BHD), Bar Vertical Discrepancy (BVD), Bar Conical Discrepancy (BCD) calculated on the means of the 18 measurements from each bar corresponding to the blue, orange and green lines shown in the figure respectively.

light ( 500 lux). Three consecutive scans were taken, each within $20 \pm 2 \mathrm{~min}$. Those scans were used to create 3 STL files which were code-named and sent to the lab by e-mail.

\subsection{Design of parallel screw-retained bars}

A CAD of a long-span, implant-supported, screwretained at implant level, parallel bar on the digitized PRM was created by an experienced dental technician with the exoCAD software (ExoCADDentalCAD v6136, 2016. Exocad GmbH, Darmstadt Germany) (Fig. 4).

The designed bar was adjusted so that it would best fit the supporting implants at each of the six acquired digital models and a unique code-name was given to each design. In this way six similar designs were created, three for the CTM group and three for the IOS group.

\subsubsection{Manufacturing of the bars}

Six parallel screw-retained bars were manufactured with the CAM - Selective Laser Melting (SLM) technique utilizing a three dimensions (3D) printer certified for dental use (TruPrint 1000 Multilaser, TRUMPF GmbH, Ditzingen, Germany). The bars were produced from a Co-Cr dental alloy powder (Mediloy $\mathrm{S}-\mathrm{CO}^{\mathrm{Tm}}, \mathrm{Bego}^{\oplus}$, Bremer Goldschlägerei Wilh. Herbst GmbH, Bremen, Germany, LOT\# P180709B). The bars were manufactured on one plate with the designated printing sequence, followed by the appropriate stress relieving process (Fig. 5). Finally, the bars were removed from the base plate, supporting pins were trimmed and finishing procedures were applied.

2.2.2. Marginal fit assessment

The marginal fit of the bars was evaluated with two methods. Initially each bar was examined radiographically on the PRM, implementing the 


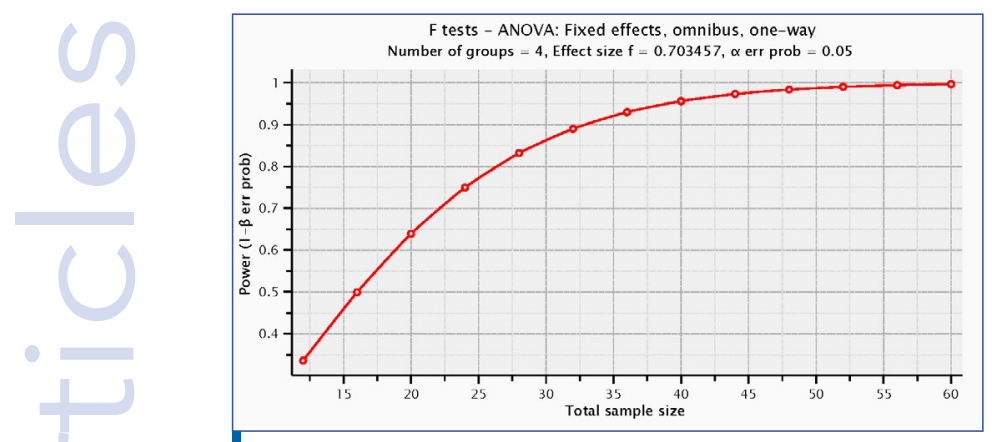

Figure 9. Power-Sample size plot created with the G*Power software, indicated for the a-priori calculation of adequate sample size for F-tests for a certain power level given the $\mathrm{a}$-error probability and the effect size.

parallel cone technique. The parallel bars were placed on the PRM and the prosthetic screws were tightened in the sequence $11,17,14$ with a standardized minimal torque $10 \mathrm{Ncm}$.

Next, the MF was measured through a nondestructive method implementing the negative replica (NR) technique and a modification of the digital image analysis sequence (DIAS), which was previously described and validated [15]. The parallel bars were seated directly on the three implant analogs and secured with the designated prosthetic screws. For the production of NR, a customized Replica Production Device (RPD) was utilized. The RPD incorporated three parallel implant analogs identical to those utilized in the PRM. The analogs were placed at the same relevant positions as the PRM, verified by two interchangeable verification jigs, one produced on the PRM and one on the RPD (Fig. 6).

The RPD facilitated the simultaneous production of three NRs, one for each implant-bar connection. The NRs were made from light viscosity addition silicone (Image PVS Super light body fast, Dental Line Ltd, Piraeus, Greece) in specialized cylindrical copper trays. After polymerization of the A-silicon, the bar was removed and the three specialized copper trays were detached from the RPD. The NRs were removed from the trays, trimmed, marked and sectioned in a sample intersection device (SID). SID allowed the reproducible section of the cylindrical NR in six $60^{\circ}$ sectors (Fig. 7). One NR was created for each of the three implant-bar connections and the aforementioned procedure facilitated the assessment of the MF at 18 points on every bar.

\subsection{Digital Image Acquisition and Analysis}

Following a standardized procedure the NR slices were examined under an optical microscope (Digital Microscope Leica DM 4000 B, Leica Microsystems, Mannheim, Germany) with a mounted camera at 320x final magnification. Photomicrographs were taken and stored in an external hard disc. The microscope settings were adjusted for maximum field of view, minimal depth of field and highest resolution for the selected magnification. External additional lighting

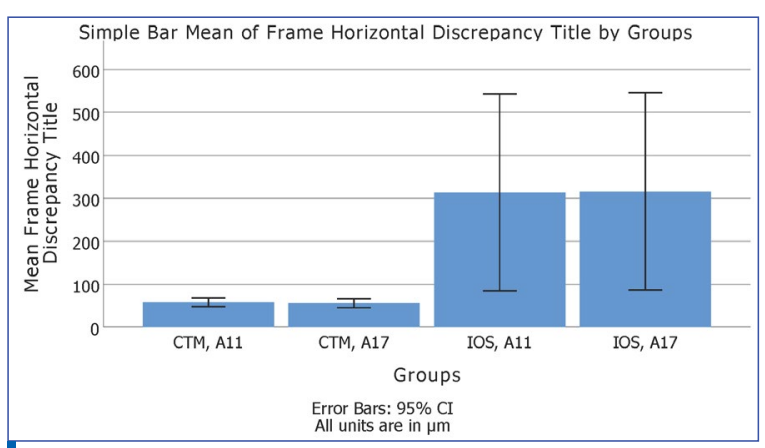

Figure 10. Bar charts of the mean BHD in $\mu \mathrm{m}$ for every experimental group separately. The confidence interval i-bars are drawn in black lines. All differences are statistically significant $(p<0.05)$ except from those between groups of the same impression technique.

sources were utilized, increasing the illumination at the stage at a mean value of 57000 lux. In the acquired images one pixel corresponded to $0.556 \mu \mathrm{m}$.

A DIAS was applied for the analysis of the captured images [15]. Each image showed the marginal fit at a sixth of the periphery of every implant-bar connection. The dark area in the photomicrograph of the NR slice corresponded to the empty space left by the analog and the bar assembly and the purple illuminated area corresponded to the space surrounding the assembly. If there was a gap between the connected components, it was presented as a characteristic elongated light purple protrusion towards the dark area of the image (Fig. 8). The image processing software Photoshop (Adobe Photoshop CS 5 V12.0.4 x64, Adobe Systems Inc.) was utilized for each image. The outline of the bar was traced and highlighted utilizing a sensitive digitizer (Bamboo CTH-470/S, Wacom, Toyonodai, Japan). Furthermore, the implant analog outline was superimposed at the best perceived fit position on the acquired image. One-pixel thick lines were drawn and the processed images saved without compression.

The standard geometry of the implant analogs in this experiment facilitated the a-priori drawing of the component outline. The analog outline included a marking point at the conical part of the component and two-line extensions from the inner edge of the shallow platform at the margin of the analog. These additions would aid the measurements on a next step.

\subsubsection{Measurements}

The marginal fit was evaluated on each photomicrograph through three dependent variables: Horizontal discrepancy (HD), Vertical discrepancy (VD) and Conical discrepancy (CD), measured in $\mu \mathrm{m}$. VD and HD were defined as the length of the line segment from the internal edge of the shallow platform of the utilized implant analog extending perpendicularly or in parallel towards the outline of the bar, respectively. The conical discrepancy was geometrically defined at the conical part of the internal hexagon of the utilized implants. Following a standardized procedure, measurements were taken 


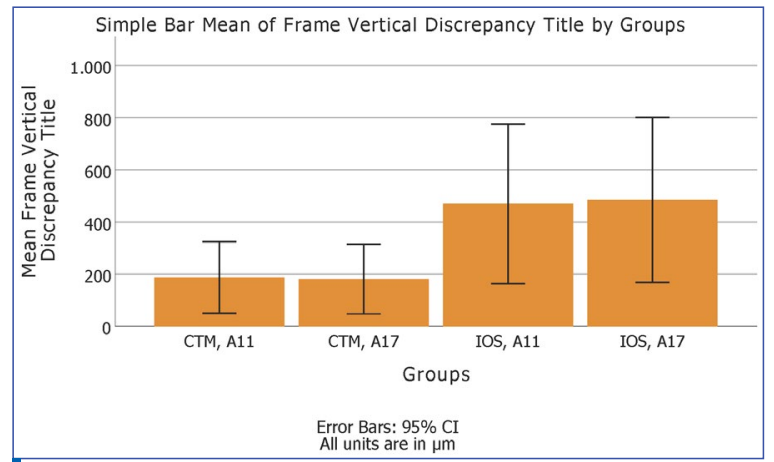

Figure11. Bar charts of the mean BVD in $\mu \mathrm{m}$ for every experimental group separately. The confidence interval i-bars are drawn in black lines. None of the differences is statistically significant (ns).

with the open-source software Image J (Image J 1.52p, National Institutes of Health, Bethesda, MD, 20892 USA) on the processed image. The measurements were automatically stored, transferred and organized for statistical analysis utilizing programs. The overall marginal fit of each bar was quantitatively evaluated with 3 indices: Bar Horizontal Discrepancy (BHD), Bar Vertical Discrepancy (BVD), Bar Conical Discrepancy $(B C D)$. These were calculated on the means of the measurements of the HD, VD and CD respectively.

2.3.2. Sample size

The marginal fit of the six bars ( 3 from the CTM and 3 from IOS) was also evaluated depending on the screw tightening sequence, forming two subgroups: Group A11 and Group A17. In group A11 the first tightened screw was at the most proximal implant analog (11), followed by the one at the most distal implant analog (17) and finally at the one in the middle (14). In group A17 the screws were tightened on the sequence $17,11,14$. Deriving from the combination of the factors, impression technique and first tightened screw, 4 groups were formed and compared in this experiment. The NR technique was run twice for the samples in these groups, doubling the data. One researcher ran the experiment. The groups are summarized in Table 1.

\subsubsection{Statistical analysis}

The data were statistically analyzed and graphs were drawn with the SPSS software (SPSS for Windows 64bit edition, V25. IBM Corp.). Descriptive statistics were computed. The normality of the data was examined by Shapiro-Wilk tests, Q-Q plots and corresponding histograms. A one-way Analysis of Variance (ANOVA) was conducted for each of the depended variables and Tukey HSD post hoc tests were utilized to locate the differences $(a=0.05)$. The effect sizes were computed and a power analysis was conducted post hoc with the open-source software GPower $[41,42]$.

\section{RESULTS}

Four groups with 24 samples each were formed. 432 digital images were analyzed in total and 1296 measurements were taken from those images.

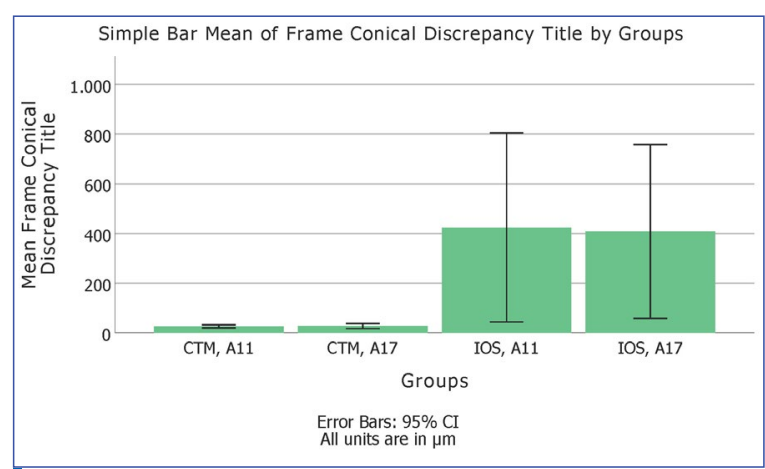

Figure 12. Bar charts of the mean $B C D$ in $\mu \mathrm{m}$ for every experimental group separately. The confidence interval i-bars are drawn in black lines. None of the differences is statistically significant (ns).

The descriptive statistics per group are summarized in Table 2 together with the results of the ShapiroWilk test of normality for relatively small sample sizes. The latter examined if the distribution of data differed significantly from the normal distribution. No significant differences were found ( $P>.05 \mathrm{~ns})$, hence parametric tests were run.

The one-way ANOVA showed a statistically significant difference between groups for the BHD $\left(F(3,20)=5,558, P<, 01, \omega=, 60, \eta^{2}=0,45\right.$, Power $(1-\beta$ err prob) $=94 \%)$. A significant difference was also found between groups for the $\operatorname{BVD}(F(3,20)=3,299, P<, 05$, $\omega=15, \eta^{2}=0.33$, Power $(1-\beta$ err prob) $=75 \%)$, and between groups for the $B C D$ differences were also statistically significant $(F(3,20)=4,996, P<, 05, \omega=, 58$, $\eta^{2}=0.43$, Power $(1-\beta$ err prob) $=91 \%)$. The Sample Size -Power analysis diagram regarding the variable BVD is presented (Fig. 9).

Tukey's post hoc tests were run to reveal the differences by comparing the means of the different groups. The results of these tests are briefly summarized next. BHD was significantly different between groups [CTM-A11] $(M=57,91, S E=4.05)$ [IOS-A11] $(M=313,59, S E=89,16)(P<.05),[$ [CTM-A11] $(M=57,91, S E=4.05)-[[O S-A 17](M=315,90, S E=89,37)$ $(\mathrm{P}<.05),[C T M-A 17](M=55,58, S E=4.07)-[I O S-A 11]$ $(M=313,59, \quad S E=89,16) \quad(P<.05)$ and $[C T M-A 17]$ $(M=55,58, S E=4.07)-[I O S-A 17](M=315,90, S E=89,37)$ $(\mathrm{P}<.05)$.

The implant-supported bars produced after a closed tray technique with Monophase PVS impression material either with their most mesial screw tightened first or the most distal one had a mean horizontal discrepancy between the bar and the implant, which was significantly smaller from that of bars produced after an intraoral scan independedly of the screw tightening sequence.

The post hoc tests could not detect the significant differences for the BVD vertical discrepancies at the marginal fit $(P>.05)$. Furthermore, the post hoc tests could not reveal the significant differences between groups for the variable $B C D$. None the less, the [CTM-A11] $(M=26,39, S E=2,21)-$ [IOS-A11] $(M=423,99, S E=147,872)$ comparison of $B C D$ means 
although not significant (ns) had $\mathrm{P}=0.50$ (ns) and the [CTM-A17] $(M=27.72, S E=3,83)-[I O S-A 11]$ $(\mathrm{M}=423,99, \mathrm{SE}=147,872)$ comparison had $\mathrm{P}=0.51$ (ns). These results were graphically drawn as bar charts with the SPSS software. The mean BHD, BVD and $B C D$ were drawn as bar charts with the $95 \%$ Confidence interval shown for every group (Fig. 10, Fig. 11, Fig. 12).

\subsection{Radiological results}

The analysis of the digital X-Rays taken directly at the PRM facilitated vertical and horizontal discrepancy measurements at the mesial and distal sides of every implant-bar connection. The mean values of these measurements $\mathrm{CTM} \mathrm{HD}=67 \mu \mathrm{m}, \mathrm{IOS} \mathrm{HD}=322 \mu \mathrm{m}$ and CTM VD $=67 \mu \mathrm{m}, \mathrm{IOS}$ VD $=689 \mu \mathrm{m}$ are comparable with the BHD and BVD of the [CTM-A11] and [IOS-A11] groups, shown in the descriptive statistics table.

\section{DISCUSSION}

This study compared the marginal fit of implantsupported, long span, parallel bars, produced after a fully digital versus a partially digital workflow. Within the limitation of this study the null hypothesis that there will be no differences among groups in all three marginal fit indices was rejected. Additionally, within the limitations of this study, the partially digital workflow combining conventional impressions resulted in prostheses with better marginal fit. The fully digital workflow implementing an intraoral scanning systemfor the directdigitization of themaxillaresulted in implant-supported bars that exhibited marginal discrepancies, which could not be considered as clinically acceptable. Digital impression is a key step in the outcome of a completely digital workflow. Complete arch scanning is associated with larger deviations as compared to partial arch scanning [2224]. It has been found that the first scanned quadrant is recorded more accurately in comparison to the one that follows [27]. This laboratory study included complete arch scanning of a simulated partially edentulous maxilla under controlled lighting conditions. It has been found that artificial lighting can affect the scanning procedure [25]. The scanning initiated from the dentate quadrant, which provided orientation points for the stitching of acquired data. The quadrant with the implants was scanned later. Therefore, both deteriorating factors that have been associated with lower accuracy have been combined in this study, which could explain the unacceptable outcomes of the completely digital workflow. It has been found that by increasing the distance between implants the intraoral scanning precision is decreased [29]. Flügge et al. found that the implant system might also affect the impression accuracy [23]. The MIS -Seven ${ }^{\mathrm{m}}$ implant system, however, was accompanied with scan-bodies with non-reflecting surface and high enough to notably protrude from the mucosa even when the implants were placed relatively deep. Additionally, the scan bodies had flattened shape and elongated at the proximal-distal dimension, which facilitated the partial capture in a single frame with the IOS wand of the two most distant successive implant analogs 14 and 17 at the PRM. Nevertheless, the marginal discrepancies at the IOS group were not acceptable. Probably there might not have been enough orientation points to accurately stitch the frames on the edentulous area of the PRM.

Huang et al. found in their study that when a scan body includes an extensional structure, the scanning accuracy is significantly improved [35]. Although several methods are applied for the assessment of the margin, in this study the NR technique was selected $[11,17]$. The MF could be assessed with direct in-situ observation as well [18]. However, direct observation relies only on one-dimensional measurements at the observed gap between examined components. Alternatively, samples could be embedded in resin material and following a destructive method, their sections could be examined under a microscope [11]. Nevertheless, such a technique would have included several steps and in case an electron microscope would have been utilized, it would have been also a time-consuming approach and costs would have been increased as well [16]. In a previous study DIAS, a recently developed and reliable stepwise procedure, has been implemented for the assessment of the crown margin on cemented implant-supported crowns [15]. Because of its non-destructive approach, the NR technique could be applied in clinical studies, given appropriate modifications are introduced and in ex-vivo studies. It is a feasible tool for the quality assessment at the numerous stages of the prostheses production $[13,14]$. The strict and clear criteria applied in this study for the evaluation of MF, minimized observer subjectivity, facilitated reliable measurements and eliminated loss of data.

In this study, the VD found for the CTM group were smaller as compared to the IOS group. This trend was also reported byLoRussoetal [6].Theimplementation of the NR technique in this study also facilitated the evaluation of HD. Such measurements are indicative of the quality of the produced prosthesis. In this study the parameters BHD and BCD were assessed as overall indication of the mean HD and the mean VD at the restoration margin respectively. The shape of the internal connection implants like the ones that were implemented in this study presents complex features like conical internal walls. Such features are common in newer designs with steeper conical walls featuring Morse taper connections. Such features might affect the retention and the quality of the mechanical connection [8]. Therefore, an additional parameter was evaluated in this study, the $B C D$, as an evaluation of the near margin quality of the connection at the conical part of the internal connection implants that were used. BCD was the 
mean discrepancy between the implant analog and the prosthesis observed $120 \mu \mathrm{m}$ within the inclined internal walls of the implant analog.

There is no consensus about the clinically acceptable marginal fit. However, most studies report a range between $50-200 \mu \mathrm{m}$. In this study the groups that included the parallel bars that were manufactured after a traditional impression with the closed tray technique presented discrepancies within that range. The observed discrepancies might be overestimated since the prosthesis was fixed on the implant analogs with prosthetic screws tightened with a minimal torque $(10 \mathrm{Ncm})$. An increased torque on the other hand might also amplify the tension and therefore compromise the passivity of fit. In this study, the marginal fit of the implant-supported bar produced after an impression with the traditional closed tray technique with VPS impression material was comparable with the results found by Lin WS et al [30]. In this study the marginal fit of bars created after an intraoral scanning was not acceptable, exceeding $1000 \mu \mathrm{m}$ gaps in some cases. Andersen FS et al., in their study using the iTero system for implant supported mandible complete dentures, found similarly unacceptable marginal fit levels [36]. Their explanation for those results was the lack of anatomical structures which could facilitate the orientation of the images by the scanner software. Earlier, Patzelt SB et al. found comparable results regarding intraoral scanners used in edentulous patients, concluding that such systems should be avoided for similar cases [37]. On the contrary Kim SY et al. found the iTero system had similar accuracy as the impression with addition silicone [38]. In their study however they utilized a plaster model of a partially edentulous case, which facilitated the orientation of the images by the scanner software. Keul et al. (2020) found that the iTero IOS had comparable results as the traditional impression technique. However, as compared to this study they utilized a more recent model with updated software [39]. It seems that differences in the connection type in combination with the implant inclination might affect the accuracy of the impressions especially for the internal connection type. That might be explained by the increased contact surface of the impression coping with the implant making the removal of the impression harder after the polymerization of the impression material. Additionally, the number and the relative positions of implants in the mesial-distal orientation might also affect the removal of the impression after setting [20]. The intraoral scanning systems seem to have adequate accuracy for single crowns and short bridges [34,40]. The complete digital workflow for constructing implant supported prostheses might raise additional limitations. In this study, it was found that the digital libraries provided by MIS only included antirotation design for the implant-level connection abutments. They suggest the use of prefabricated components without antirotation design, which would later be connected with the rest of the metallic frame. The antirotation connection type might also be a reason for the unacceptable marginal gaps encountered in the intraoral scanner groups in this study. Furthermore, the older software version of the utilized scanning system might also be a reason.

In this study, the effect of the impression technique on the marginal fit of implant-supported parallel bars was evaluated at implant level. The field of view of the scanner sensor facilitated the simultaneous capture of two consecutive scanning posts attached to the three implant analogs in that region. The posts at positions 11 and 14 were simultaneously covered in a larger part of their surface than the posts at positions 14 and 17 . This might have contributed to the insertion of errors during scanning, due to lack of adequate orientation points. Flügge TV et al, in their study, measured the distances and the inclinations of scan posts on the digital models and underlined the negative correlation between accuracy of intraoral scanning systems and the distance between scan posts [29]. In this study, although the PRM simulated the color of the tissues of the oral cavity and it was accordingly polished, clinically saliva, blood and humidity might be present, posing additional challenges for an accurate scan. Additionally, the scanner wand was bulky which probably poses an extra limitation for accessing distal areas clinically. Moreover, in this study implant analogs were placed parallel to each other, which might have favored the results. On the contrary, Gracis $S$ et al. and Lee $\mathrm{HJ}$ et al., found that inclined implants could hinder an accurate scan [31,32]. Additionally, in this study implant analogs were used and not actual implants. No data could be found for the accuracy of these components. Furthermore, the analogs were located under $3-4 \mathrm{~mm}$ of simulated mucosa, which is relatively deep. This might have a negative effect on the accuracy of the impression as well as the intraoral scan [28]. Especially for the latter, the scan posts were deeply submerged under the mucosa obscuring a large portion of their surface. Hence, there were less points of orientation available for the software to recognize for an accurate placement of the implant in the CAD software.

The bars in this experiment were manufactured with a 3D printing technique using $\mathrm{Co}-\mathrm{Cr}$ alloy powder. Although the SLM frameworks are produced with acceptable accuracy, the surface of the components is rough. Such quality is not favorable when the components are intended for precision connections such as telescopic crowns and bars. Additionally, the coarse surface posed a challenge for the edge recognition on the negative replica. The marginal fit was examined in this study with two techniques. One was a direct technique, applicable clinically, by taking digital radiographs with the parallel cone technique of the analog-bar assembly. Yet, the radiographs revealed the quality of the implant-bar 
connection was inadequate for performing accurate measurements, due to a relatively low resolution. Furthermore, only two points at the margin could be examined, one distally and one mesially of every analog-prosthesis connection. Wahle et al. concluded that the marginal fit is not adequately evaluated only with radiographs [9]. The other technique was the negative replica technique in combination with a DIAS [15].

\subsection{Clinical relevance}

The intraoral scanning systems have undoubtedly advantages; however, regarding the implementation of such systems in implant dentistry, one should proceed with caution as not acceptable fit levels might result.

Furthermore, the availability of ready-to-use digital designs of components needs to be assessed in advance since proprietary rights might impose limitations leading to different treatment approaches.

\section{CONCLUSION}

The implementation of the negative replica technique in combination with the modified DIAS was a viable, non-destructive method to simultaneously assess the horizontal, vertical and conical fit of the implant-supported bars on three implants in this study.

Within the limitations of this study, it was concluded that all the examined combinations of impression techniques and screw tightening sequences resulted in marginal discrepancies, detectable with the applied method. The simulated intraoral scanning with the iTero system in the setup of the present study resulted in unacceptable marginal gaps, visualized on replica segments under the optical microscope. In this study, the closed tray impression technique with addition silicon resulted in better marginal fit levels, when examined with the applied method, while the screw tightening sequence does not seem to affect the prosthesis adaptation on the implants.

\section{CONFLICT OF INTEREST}

The authors declare no conflict of interest.

\section{ACKNOWLEDGMENTS}

The authors thank Professor Dr. Demetrios Halazonetis for his contribution with the iTero IOS system. The authors also thank the Dental Technician loannis Malindretos for his contribution with the working models and CADs. The authors appreciate the donation of the 3D printed - Laser Sintering bars from the Dental Technician Laboratory Ergastiri 86 Ltd expressing their thanks. The authors also express their thanks to George Villias Dipl. Ing., MSc for his assistance with coding the programs "Coding_Input" and "Data_Table_Generator_V5FX" for the automated data transfer for statistical analysis.

\section{AUTHOR CONTRIBUTIONS}

TP and AV: the conception and design of the study. AV: acquisition of data. AV, TP, NP, HK and GP: analysis and interpretation of data. AV, NP, HK: drafting the article. TP, HK and GP: revising it critically for important intellectual content. AV, TP, NP, HK and GP: final approval of the version to be submitted.

\section{REFERENCES}

1. Polzer I, Schimmel M, Müller F, Biffar R. Edentulism as part of the general health problems of elderly adults. Int Dent $J$. 2010;60(3):143-155. doi: 10.1922/IDJ_2184Polzer13. PMID: 20684439.

PubMed Google Scholar Scopus WoS

2. Kim JJ. Revisiting the removable partial denture. Dent Clin North Am. 2019;63(2):263-278. doi: 10.1016/j.cden.2018.11.007. PMID: 30825990.

Full text links CrossRef PubMed Google Scholar Scopus

3. Kossioni AE, Karkazis HC. Development of a Gerodontology course in Athens: a pilot study. Eur J Dent Educ. 2006;10(3):131136. doi: 10.1111/j.1600-0579.2006.00402.x. PMID: 16842586. Full text links CrossRef PubMed Google Scholar Scopus

4. Tribst JP, de Araújo RM, Ramanzine NP, et al. Mechanica behavior of implant assisted removable partial denture for Kennedy class II. J Clin Exp Dent. 2020;12(1):e38-e45. doi: 10.4317/ medoral.56533. PMID: 31976042; PMCID: PMC6969961.

Full text links CrossRef PubMed Google Scholar Scopus 5. Mello CC, Lemos CAA, de Luna Gomes JM, et al. CAD/CAM vs conventional technique for fabrication of implant-supported frameworks: a systematic review and meta-analysis of in vitro studies. Int J Prosthodont. 2019;32(2):182-192. doi: 10.11607/ ijp.5616. PMID: 30856643.

Full text links CrossRef PubMed Google Scholar Scopus WoS 6. Lo Russo L, Caradonna G, Biancardino M, et al. Digital versus conventional workflow for the fabrication of multiunit fixed prostheses: a systematic review and meta-analysis of vertical marginal fit in controlled in vitro studies. J Prosthet Dent. 2019;122(5):435-440. doi: 10.1016/j.prosdent.2018.12.001. PMID: 31027957.

Full text links CrossRef PubMed Google Scholar Scopus WoS 7. Bronson MR, Lindquist TJ, Dawson DV. Clinical acceptability of crown margins versus marginal gaps as determined by pre-doctoral students and prosthodontists. J Prosthodont. 2005;14(4):226-232. doi: 10.1111/j.1532-849X.2005.00048.x. PMID: 16359478.

Full text links CrossRef PubMed Google Scholar

8. Kofron MD, Carstens M, Fu C, Wen HB. In vitro assessment of connection strength and stability of internal implant-abutment connections. Clin Biomech (Bristol, Avon). 2019;65:92-99. doi: 10.1016/j.clinbiomech.2019.03.007. PMID: 31005695.

Full text links CrossRef PubMed Google Scholar Scopus WoS 9. Wahle WM, Masri R, Driscoll C, Romberg E. Evaluating ceramic crown margins with digital radiography. J Prosthet Dent. 2018;119(5):777-782. doi: 10.1016/j.prosdent.2017.07.020. PMID: 28969920.

Full text links CrossRef PubMed Google Scholar Scopus WoS 10. Agar JR, Cameron SM, Hughbanks JC, Parker MH. Cement removal from restorations luted to titanium abutments with simulated subgingival margins. J Prosthet Dent. 1997;78(1):43-47. doi: 10.1016/s0022-3913(97)70086-6. PMID: 9237145.

Full text links CrossRef PubMed Google Scholar Scopus WoS 11. Son K, Lee S, Kang SH, et al. A comparison study of marginal and internal fit assessment methods for fixed dental prostheses. 
J Clin Med. 2019;8(6):785. doi: 10.3390/jcm8060785. PMID: 31159460; PMCID: PMC6617221.

Full text links CrossRef PubMed Google Scholar WoS

12. Sorensen JA. A standardized method for determination of crown margin fidelity. J Prosthet Dent. 1990;64(1):18-24. doi: 10.1016/0022-3913(90)90147-5. PMID: 2200878.

Full text links CrossRef PubMed Google Scholar Scopus WoS 13. Villias A, Niedermeier W. Influence of three factors on cement Profile. J Dent Res. 2014;93(Spec Iss B): 763. Available from: https://iadr.abstractarchives.com/abstract/14iags-187793/ influence-of-three-factors-on-cement-profile

Google Schola

14. Villias A, Niedermeier W. Finishing effects on cement surfaces at different marginal fit levels. J Dent Res 2014;93(Spec Iss C):442. Available from: https://iadr.abstractarchives.com/abstract/ per14-191727/finishing-effects-on-cement-surfaces-at-differentmarginal-fit-levels.

15. Villias AA, Kourtis SG, Karkazis HC, Polyzois GL. In vitro validation of Digital Image Analysis Sequence (DIAS) for the assessment of the marginal fit of cement-retained implantsupported experimental crowns. Int J Implant Dent. 2021;7(1):12 doi: 10.1186/s40729-021-00290-6. PMID: 33585971.

Full text links CrossRef PubMed Google Scholar WoS 16. Oyagüe RC, Sánchez-Turrión A, López-Lozano JF, SuárezGarcía MJ. Vertical discrepancy and microleakage of lasersintered and vacuum-cast implant-supported structures luted with different cement types. J Dent. 2012;40(2):123-130. doi: 10.1016/j.jdent.2011.11.007. PMID: 22108101.

Full text links CrossRef PubMed Google Scholar Scopus WoS 17. Gassino G, Barone Monfrin S, Scanu M, et al. Marginal adaptation of fixed prosthodontics: a new in vitro 360-degree external examination procedure. Int J Prosthodont. 2004;17(2): 218-223. PMID: 15119875. http://www.quintpub.com/userhome/ iip/ijp 17 2 Gassino 15.pdf

PubMed Google Scholar Scopus WoS

18. Gonzalo E, Suárez MJ, Serrano B, Lozano JF. A comparison of the marginal vertical discrepancies of zirconium and metal ceramic posterior fixed dental prostheses before and after cementation.J Prosthet Dent. 2009:102(6):378-384 doi: 10.1016/ S0022-3913(09)60198-0. PMID: 19961996.

Full text links CrossRef PubMed Google Scholar Scopus 19. Nissan J, Rosner O, Rosen G, Naishlos S, Zenziper E, Zelikman H, Lavi D, Chaushu L. Influence of vinyl polysiloxane impression techniques on marginal fit of metal frameworks for fixed partial dentures. Materials (Basel). 2020;13(20):4684. doi: 10.3390/ ma13204684. PMID: 33096749; PMCID: PMC7589621. Full text links CrossRef PubMed Google Scholar Scopus WoS 20. Kim S, Nicholls Jl, Han CH, Lee KW. Displacement of implant components from impressions to definitive casts. Int J Oral Maxillofac Implants. 2006;21(5):747-755. PMID: 17066636. http:// medlib.yu.ac.kr/eur_j_oph/ijom/IJOMI/ijomi_21_747.pdf PubMed Google Scholar Scopus WoS

21. Tallarico M. Computerization and digital workflow in medicine: focus on digital dentistry. Materials (Basel). 2020;13(9):2172. doi: 10.3390/ma13092172. PMID: 32397279; PMCID: PMC7254335.

Full text links CrossRef PubMed Google Scholar Scopus WoS 22. Borbely J. Low-quality evidence suggests digital impressions (dis) and conventional impressions are comparable for marginal and internal fit, very-low quality evidence for interproximal and occlusal contacts is insufficient to draw conclusion and there is no evidence regarding survival of full-coverage restorations. J Evid Based Dent Pract. 2019:19(4):101347. doi: 10.1016/j. jebdp.2019.101347. PMID: 31843174

Full text links CrossRef PubMed Google Scholar WoS 23. Marghalani A, Weber HP, Finkelman M, Kudara Y, El Rafie K, Papaspyridakos P. Digital versus conventional implant impressions for partially edentulous arches: An evaluation of accuracy. J Prosthet Dent. 2018;119(4):574-579. doi: 10.1016/j. prosdent.2017.07.002. PMID: 28927923.

Full text links CrossRef PubMed Google Scholar Scopus WoS 24. Wismeijer D, Joda T, Flügge T, et al. Group 5 ITI consensus report: digital technologies. Clin Oral Implants Res. 2018;29 Suppl 16:436-442 doi: $10.1111 /$ clr.13309. PMID. 30328201. Full text links CrossRef PubMed Google Scholar Scopus WoS 25. Arakida T, Kanazawa M, Iwaki M, et al. Evaluating the influence of ambient light on scanning trueness, precision, and time of intra oral scanner. J Prosthodont Res. 2018;62(3):324-329. doi: 10.1016/j.jpor.2017.12.005. PMID: 29397353.

Full text links CrossRef PubMed Google Scholar Scopus WoS 26. Takeuchi Y, Koizumi H, Furuchi M, et al. Use of digital impression systems with intraoral scanners for fabricating restorations and fixed dental prostheses. J Oral Sci. 2018;60(1):17. doi: 10.2334/josnusd.17-0444. PMID: 29576569. Full text links $\underline{\text { CrossRef PubMed Google Scholar Scopus WoS }}$
27. Giménez B, Özcan M, Martínez-Rus F, Pradíes G. Accuracy of a digital impression system based on parallel confocal laser technology for implants with consideration of operator experience and implant angulation and depth. Int J Oral

Maxillofac Implants. 2014:29(4):853-862. doi: 10.11607/jomi.3343. PMID: 25032765

Full text links CrossRef PubMed Google Scholar Scopus WoS 28. Gimenez-Gonzalez B, Hassan B, Özcan M, Pradíes G. An in vitro study of factors influencing the performance of digital intraoral impressions operating on active wavefront sampling technology with multiple implants in the edentulous maxilla. J Prosthodont. 2017:26(8):650-655. doi: 10.1111/jopr.12457. PMID: 26934046.

Full text links CrossRef PubMed Google Scholar Scopus WoS 29. Flügge TV, Att W, Metzger MC, Nelson K. Precision of dental implant digitization using intraoral scanners. Int J Prosthodont. 2016;29(3):277-283. doi: 10.11607/ijp.4417. PMID: 27148990. Full text links CrossRef PubMed Google Scholar Scopus WoS 30. Lin WS, Harris BT, Elathamna EN, et al. D. Effect of implant divergence on the accuracy of definitive casts created from traditional and digital implant-level impressions: an in vitro comparative study. Int J Oral Maxillofac Implants. 2015;30(1):102-

109. doi: 10.11607/jomi.3592. PMID: 25615919.

Full text links CrossRef PubMed Google Scholar Scopus WoS 31. Gracis S, Michalakis K, Vigolo P, et al. Internal vs. external connections for abutments/reconstructions: a systematic review. Clin Oral Implants Res. 2012;23 Suppl 6:202-216. doi: 10.1111/j.1600-0501.2012.02556.x. PMID: 23062143.

Full text links CrossRef PubMed Google Scholar Scopus WoS 32. Lee HJ, Lim YJ, Kim CW, et al. Accuracy of a proposed implant impression technique using abutments and metal framework. J Adv Prosthodont. 2010;2(1):25-31. doi: 10.4047/jap.2010.2.1.25.

PMID: 21165184; PMCID: PMC2984514.

Full text links CrossRef PubMed Google Scholar Scopus WoS 33. Leeson D. The digital factory in both the modern dental lab and clinic. Dent Mater. 2020;36(1):43-52. doi: 10.1016/j. dental.2019.10.010. PMID: 31727448.

Full text links CrossRef PubMed Google Scholar Scopus WoS 34. van der Meer WJ, Andriessen FS, Wismeijer D, Ren Y. Application of intra-oral dental scanners in the digital workflow of implantology. PLoS One. 2012;7(8):e43312. doi: 10.1371/ journal.pone.0043312. PMID: 22937030; PMCID: PMC3425565.

Full text links CrossRef PubMed Google Scholar Scopus WoS 35. Huang R, Liu Y, Huang B, et al. Improved scanning accuracy with newly designed scan bodies: an in vitro study comparing digital versus conventional impression techniques for completearch implant rehabilitation. Clin Oral Implants Res. 2020;31(7):625633. doi: $10.1111 / \mathrm{cl}$.13598. PMID: 32181919.

Full text links CrossRef PubMed Google Scholar Scopus WoS 36. Andriessen FS, Rijkens DR, van der Meer WJ, Wismeijer DW. Applicability and accuracy of an intraoral scanner for scanning multiple implants in edentulous mandibles: a pilot study. J Prosthet Dent. 2014;111(3):186-194. doi: 10.1016/j. prosdent.2013.07.010. PMID: 24210732

Full text links CrossRef PubMed Google Scholar Scopus WoS 37. Patzelt SB, Emmanouilidi A, Stampf S, et al. Accuracy of full-arch scans using intraoral scanners. Clin Oral Investig. 2014;18(6):1687-1694. doi: 10.1007/s00784-013-1132-y. PMID: 24240949.

Full text links CrossRef PubMed Google Scholar

38. Kim SY, Kim MJ, Han JS, et al. Accuracy of dies captured by an intraoral digital impression system using parallel confocal imaging. Int J Prosthodont. 2013;26(2):161-163. doi: 10.11607/ ijp.3014. PMID: 23476911.

Full text links CrossRef PubMed Google Scholar Scopus WoS 39. Keul C, Güth JF. Accuracy of full-arch digital impressions: an in vitro and in vivo comparison. Clin Oral Investig. 2020:24(2):735745. doi: 10.1007/s00784-019-02965-2. PMID: 31134345. Full text links CrossRef PubMed Google Scholar Scopus WoS 40. Menini M, Setti P, Pera F, et al. Accuracy of multi-unit implant impression: traditional techniques versus a digital procedure. Clin Oral Investig. 2018;22(3):1253-1262. doi: 10.1007/s00784-017-

2217-9. PMID: 28965251.

Full text links CrossRef PubMed Google Scholar Scopus WoS 41. Faul F, Erdfelder E, Lang AG, Buchner A. G*Power 3: a flexible statistical power analysis program for the social, behavioral, and biomedical sciences. Behav Res Methods. 2007:39(2):175-191. doi: 10.3758/bf03193146. PMID: 17695343.

PubMed Google Scholar Scopus WoS

42. Faul F, Erdfelder E, Buchner A, Lang AG. Statistical power analyses using $G^{*}$ Power 3.1: tests for correlation and regression analyses. Behav Res Methods. 2009;41(4):1149-1160. doi: 10.3758/ BRM.41.4.1149. PMID: 19897823.

CrossRef PubMed Google Scholar 


\section{Aristeidis VILLIAS \\ DDS, MSc, Dr.Med.Dent., Clinical Instructor Department of Prosthodontics School of Dentistry National and Kapodistrian University of Athens, Athens, Greece}

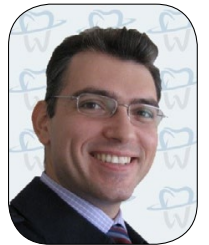

Aristeidis Villias graduated from the School of Dentistry of the National and Kapodistrian University of Athens, Greece in 2008. In 2015 he obtained his doctorate degree from the University of Cologne, Cologne (NRW), Germany after a scholarship for postgraduate studies abroad issued (2010) by the State Scholarships Foundation of the Hellenic Republic (IKY). In 2015 he also started his private practice in Piraeus, Greece. In 2019 he obtained his master's degree in Dental Biomaterials from the School of Dentistry of the National and Kapodistrian University of Athens, Greece. Since 2020 he has been Clinical Instructor in Removable Prosthodontics, School of Dentistry, National and Kapodistrian University of Athens, Greece and in the Section of Dental Technology, Department of Biomedical Sciences School of Health and Care Sciences, University of West Attica, Athens, Greece.

\section{Orestions}

\section{According to the article, the implant-supported bars manufactured after the traditional impression technique as compared to those manufactured after implementation of the intraoral scanner:}

$\square$ a. Have significantly better horizontal discrepancy at the implant-bar interface;

口b. Present undetectable discrepancies at the implant-bar interface;

口. Have inferior marginal fit at the implant-bar interface;

$\square d$. Present marginal discrepancies which are not clinically acceptable.

\section{The screw tightening sequence when seating the implant supported bar in this study seems to:}

Da. Have no effect on the marginal fit of the bar at implant level;

ab. Affect significantly the marginal fit of the bar at implant level;

Dc. Have a significant effect when the most mesial screw is tightened first;

Ud. Have a significant effect when the most distal screw is tightened first.

\section{In this study the marginal fit of the computer aided manufactured bars}

口a. Was better when a fully digital workflow was followed;

b. Was worse when a fully digital workflow was followed;

ac. Was similar either with a fully digital workflow or with a partially digital workflow;

$\square$ d. Was worse when a partially digital workflow was followed.

\section{The computer aided design of implant supported bars}

$\square$ a. Was versatile allowing smooth implementation of the conceived design;

ab. Was versatile allowing implementation of the conceived design after certain auxiliaries had been purchased;

口. Was limited by proprietary design concepts;

$\square$ d. Was not applicable in this study. 